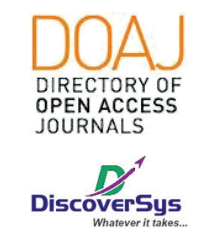

Published by DiscoverSys

\section{Flushing intramedular dengan epinefrin pada prosedur Cemented Hip Arthroplasty menstabilkan mean arterial pressure tanpa mempengaruhi profil lipid}

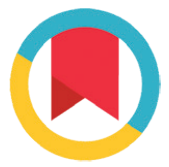

CrossMark

\author{
Aakash, ${ }^{1 *}$ Ketut Siki Kawiyana, ${ }^{2}$ I Wayan Suryanto Dusak ${ }^{2}$, Ketut Gede Mulyadi Ridia, ${ }^{2}$ \\ I Ketut Suyasa, ${ }^{2}$ I Gusti Ngurah Wien Aryana, ${ }^{2}$ I Gede Eka Wiratnaya, ${ }^{2}$ \\ Anak Agung Wiradewi Lestari ${ }^{3}$
}

\title{
ABSTRACT
}

Background: Cemented Hip Arthroplasty is the first choice of surgical treatment in fractures of neck femur and advanced hip osteoarthritis. Nevertheless, the complication, Bone Cement Implantation Syndrome can produce intra/postoperative mortality. The systemic effects of bone cement uses is hemodynamic disturbance and pulmonary embolism. These complications are thought due to the entry of semen particles into the systemic circulation caused by increased intramedullary pressure and local vasodilation. Intramedullary flushing with epinephrine after cement implantation is one of the interventions that is expected to reduce this impact. This study aims to determine the difference in hemodynamic effects and lipid profile in patients undergone flushing with epinephrine versus $\mathrm{NaCl} 0.9 \%$.

Methods: A cross-sectional study involving 30 patients who underwent Cemented Hip Arthroplasty, randomly divided into 2 groups. Surgical procedures differ only in the components used for intramedullary flushing, namely $\mathrm{NaCl} 0.9 \%$ (control) and epinephrine 1: 50000 (intervention). Vital signs are observed and recorded at minute 2,4,6,8, and 10 after cementation. Serial data were analyzed with repeated measures ANOVA. Lipid profile examination was performed before and 12 hours postoperatively and the results were analyzed with Wilcoxon-test.

Results: The study observed a decreased of mean arterial pressure (MAP) in the control group after two minutes of cementation, and reached its lowest point in the sixth minute $(p<0.05)$. In the intervention group, the decrease occurred in second to sixth minutes, but the decrease was more stable and there was no significant difference between time-point ( $p>0.05)$. There were no significant differences of triglyceride and cholesterol level before and 12 hours after the procedure $(p>0.05)$.

Conclusion: Intramedullary flushing with epinephrine after semen implantation in the Cemented Hip Arthroplasty procedure results in a minimal reduction of MAP compared to flushing without epinephrine. However, there were no difference in preoperative and postoperative cholesterol and triglyceride levels.
1Program Studi Orthopaedi dan Traumatologi, Fakultas Kedokteran Universitas Udayana, Bali, Indonesia

${ }^{2}$ Departemen Orthopaedi dan Traumatologi, Fakultas Kedokteran Universitas Udayana/RSUP Sanglah Denpasar, Bali, Indonesia

${ }^{3}$ Departemen Patologi Klinik, Fakultas Kedokteran, Universitas Udayana/ RSUP Sanglah Denpasar, Bali, Indonesia

*Korespondensi: Aakash, Program Studi Orthopaedi dan Traumatologi, Fakultas Kedokteran Universitas Udayana, Bali, Indonesia. aakash.chatani@gmail.com

Diterima: 28-06-2019 Disetujui: 09-02-2020 Diterbitkan: 01-04-2020

Keywords: Cemented Hip Arthroplasty, Bone Cement Implantation Syndrome, Epinephrine, Lipid profile.

Cite This Article: Aakash, Kawiyana, K.S., Dusak, I.W.S. 2020. Flushing intramedular dengan epinefrin pada prosedur Cemented Hip Arthroplasty menstabilkan mean arterial pressure tanpa mempengaruhi profil lipid. Intisari Sains Medis 11(1): 340-345. D0I: 10.15562/ism.v11i1.554

\section{ABSTRAK}

Latar Belakang: Cemented Hip Arthroplasty menjadi pilihan utama terapi pembedahan pada fraktur collum femoris (Neck of Femur) serta osteoarthritis sendi panggul stadium lanjut. Meskipun demikian, komplikasi Bone cement implantation syndrome dapat menghasilkan morbiditas dan mortalitas intra/pasca operasi. Efek sistemik dari penggunaan semen tulang adalah gangguan hemodinamik dan emboli paru yang diduga akibat masuknya dari partikel semen ke sirkulasi sistemik akibat peningkatan tekanan intrameduler dan vasodilatasi lokal. Flushing intramedula dengan epinefrin paska implantasi semen merupakan salah satu intervensi yang diharapkan mengurangi dampak tersebut. Penelitian ini dilakukan untuk mengetahui perbedaan dampak hemodinamik dan profil lipid pada pasien dengan flushing epinefrine dan $\mathrm{NaCl}$ 0,9\%.

Metode: Penelitian potong lintang dengan melibatkan 30 pasien yang menjalani cemented arthroplasty, dibagi rata menjadi 2 kelompok secara acak. Prosedur pembedahan hanya berbeda pada komponen yang digunakan untuk flushing intramedula, yakni $\mathrm{NaCl}$ 0,9\% (kontrol) dan epinefirn 1:50.000 (intervensi). Tanda vital diamati dan dicatat pada menit ke-2,4,6,8, dan 10 setelah sementasi. Data serial dianalisis dengan repeated measure Anova. Pemeriksaan profil lipid dilakukan sebelum dan 12 jam pasca operasi dan hasil dianalisis dengan Wilcoxon-test.

Hasil: Penurunan mean arterial pressure (MAP) pada kelompok kontrol sejak menit ke 2 setelah sementasi, dan mencapai titik terendah pada menit ke $6(p<0,05)$. Pada kelompok intervensi didapatkan penurunan terjadi pada menit ke 2 hingga ke 6 , tetapi penurunan lebih stabil dan tidak terdapat perbedaan bermakna ( $p>0.05$ ). Pada profil lipid (trigliserida dan kolesterol), tidak ditemukan perbedaan yang bermakna antara kadar sebelum operasi dan 12 jam setelah tindakan operatif $(p>0,05)$.

Kesimpulan: Flushing epinefrin paska implantasi semen pada prosedur Cemented Hip Arthroplasty menghasilkan penurunan MAP yang minimal dibandingkan flushing tanpa epinefrin. Akan tetapi, flushing epinefrin tidak memberikan perbedaan pada kadar kolesterol dan trigliserida paska operasi. 
Kata Kunci: Cemented Hip Arthroplasty, Bone Cement Implantation Syndrome, Epinefrin, profil lipid.

Cite Pasal Ini: Aakash, Kawiyana, K.S., Dusak, I.W.S. 2020. Flushing intramedular dengan epinefrin pada prosedur Cemented Hip Arthroplasty menstabilkan mean arterial pressure tanpa mempengaruhi profil lipid. Intisari Sains Medis 11(1): 340-345. D0l: 10.15562/ism.v11i1.554

\section{PENDAHULUAN}

Arthroplasty adalah suatu prosedur pembedahan penggantian komponen sendi dengan implan prostetik. Arthroplasti saat ini menjadi pilihan utama terapi pembedahan pada fraktur collum femoris (Neck of Femur) serta osteoarthritis stadium lanjut, khususnya pada penderita usia tua. Pada umumnya, teknik arthroplasti dibagi menjadi dua yaitu dengan pemberian semen tulang (cemented arthroplasty) atau tanpa semen tulang (non-cemented arthroplasty). Kedua teknik tersebut memiliki keuntungan dan kerugian masing - masing. Namun, secara umum pada penderita usia lebih tua akan lebih menguntungkan menggunakan teknik Arthroplasti dengan pemberian semen tulang. ${ }^{1,2}$

Teknik bedah yang menggunakan semen tulang (bone cement) memiliki komplikasi yang berisiko menyebabkan kematian yakni disebut sebagai Bone Cement Implantation Syndrome (BCIS). BCIS dikenal sebagai kumpulan gejala akibat masuknya partikel semen ke dalam pembuluh darah sehingga menyebabkan hipoksia, hipotensi atau keduanya. Patofisiologi terjadinya BCIS hingga saat ini belum diketahui pasti, tetapi terdapat beberapa teori teleh dikemukakan. Teori pertama terkait dengan partikel Monomer Methyl Methacrylate (MMA) yang diperkirakan mampu mengganggu aktivitas miokardium melalui hambatan penyerapan kalsium pada retikulum sarkoplasma sehingga menyebabkan vasodilatasi dan hipotensi. Pada penelitian yang dilakukan oleh Griffiths dan Solemeinha mendukung terjadinya hipotensi dengan temuan bahwa MAP menurun secara signifikan pada menit ke 5 setelah dilakukan implantasi semen. ${ }^{3,4}$ Namun teori ini gagal menunjukkan konsentrasi partikel MMA pada darah yang dapat menimbulkan efek kardiovaskular tersebut. ${ }^{5,6}$

Teori lain, yakni teori emboli merupakan yang paling banyak dikemukakan namun dengan berbagai mekanisme. Helgason memperkirakan monomer semen tulang yang masuk ke dalam peredaran darah akan menyebabkan peningkatan risiko koagulasi serta agregasi trombosit. Pada waktu yang bersamaan, panas dari polimerisasi monomer tersebut juga dapat merusak sel endotel serta menghambat penyerapan kalsium otot polos pembuluh darah dan menyebabkan angiektasis (vasodilatatsi lokal) serta penurunan tekanan darah. Statisnya aliran darah, kerusakan dinding pembuluh darah dan perubahan komponen darah inilah yang dapat menyebabkan trombosis. ${ }^{7,8}$ Peneliti lainnya mengemukakan terbentuknya emboli lemak paru akibat aglutinasi kilomikron plasma karena peningkatan tekanan intramedula yang mendorong emboli lemak dan debris tulang ke sirkulasi. ${ }^{9-11}$

Berangkat atas teori-teori tersebut, saat ini telah dilakukan beberapa usaha untuk mengurangi risiko terjadinya BCIS seperti lavage atau suction sebelum memasukkan semen ataupun implan, melakukan teknik ventilasi seperti penggunaan bor dengan ukuran lubang 4-5 mm di korteks dan pemberian obat inotropik (seperti epinefrin). Baik lavage atau suction serta teknik ventilasi bertujuan mengurangi tekanan intramedula dan mengurangi masuknya debris ke sirkulasi sedangkan pemberian epinefrin bertujuan untuk mengoptimalisasi volume intravaskuler saat terjadi efek vasodilatasi. ${ }^{12,13}$ Walaupun demikian, belum diketahui ada tidaknya perbedaan penurunan MAP pada pasien yang menjalani operasi cemented hip arthroplasty pada pasien yang menggunakan flushing epinefrin atau tanpa flushing epinefrin serta perubahan profil lipid dalam darah sebelum dan 12 jam paska operasi.

\section{METODE}

Penelitian potong lintang analitik dilakukan di Ruang Operasi Instalasi Bedah Sentral dan Instalasi Gawat Darurat Rumah Sakit Umum Pusat Sanglah Denpasar, Bali, Indonesia pada bulan Januari 2019. Semua proses pembedahan akan dilakukan oleh satu dokter spesialis Orthopaedi dan Traumatologi dan satu residen sebagai asisten. Sampel penelitian diambil dari populasi pasien dengan fraktur colum femur dan osteoarthritis sendi panggul stadium lanjut yang menjalani tindakan pembedahan berupa Arthroplasty sendi. Pasien memberikan persetujuan mengikuti penelitian setelah dijelaskan mengenai tindakan pembedahan dan prosedur penelitian dengan penjaminan kerahasaiaan data pasien. Sampel yang memenuhi persyaratan lalu secara acak dimasukan ke kelompok kontrol dan kelompok perlakuan. Kriteria inklusi diantaranya pasien perempuan atau laki-laki dengan umur $>60$ tahun, fraktur tulang panggul dengan klasifikasi Garden 2, 3 atau 4, osteoartritis tulang panggul Kellgren-Lawrence grade 3 atau 4, fraktur patologis pada proksimal femur. Kriteria ekslusi meliputi hipertensi, diabetes mellitus, penyakit paru, 
penyakit hematologi, alergi terhadap epinefrin, gagal jantung kongestif (kelas fungsional New York Heart Association III atau IV), adanya tanda hipertensi pulmoner, adanya fraktur tulang panggul, dan riwayat alergi berat. Sampel dikatakan drop-out jika pasien meninggal di meja operasi dan timbul faktor ekslusi selama penelitian. Protokol penelitian telah mendapatkan persetujuan dari Komite Etik Penelitian FK Unud/RSUP Sanglah (no. 152/ UN14.2.2.VII.14/LP/2019)

Prosedur operasi dimulai dari pasien dalam posisi lateral dekubitus dibawah pengaruh anestesi. Dilakukan desinfeksi lapangan operasi dan drapping. Dilakukan insisi posterolateral dengan metode Moore (Moore approach), dan diseksi pada fascia lata dan muskulus gluteal. Insisi diperdalam hingga tampak otot short rotator, insisi short external rotator hingga tampak kapsul sendi dan dilakukan capsulotomy, hingga tampak sendi panggul. Selanjutnya dilakukan osteotomy pada femoral neck untuk femoral preparation, reaming, lateralisasi, kemudian dilakukan flushing medulla dengan $\mathrm{NaCl}$ 0.9\% (control), atau flushing dengan epinephrin 1:50.000 (intervensi). Setelah flushing, diikuti dengan dry gauze packing. Implantasi semen tulang dilakukan secara manual ke dalam sumsum tulang femur dengan tangan, hingga berwarna sedikit pucat, kemudian dipasang femoral stem, dilanjutkan dengan femoral head.

Paska implantasi semen dilakukan pemantauan serial. Monitor elektrokardiogram (M8004A, Philips Healthcare, Belanda) digunakan untuk memantau tekanan darah (termasuk MAP), denyut jantung, elektrokardiogram (EKG), dan saturasi oksigen perifer (SPO2) pada semua pasien. Nilai tersebut dicatat sebelum menggunakan semen tulang dan data secara serial dicatat setiap 2 menit (menit ke 2, 4, 6, 8, dan 10) setelah implantasi semen tulang.

Data yang diperoleh dianalisis dengan analisis deskriptif, analisis normalitas dan homogenitas dan uji inferensial. Uji Normalitas data dengan uji Saphiro-Wilk, uji Homogenitas dengan Levene's Test for Equality of Variance. Analisis Inferensial, bila distribusi normal dilakukan uji repeated measure analysis of variance (ANOVA). Bila distribusi tidak normal dilakukan uji non-parametrik dengan Mann-Whitney U Test. Bila hasil ANOVA signifikan secara statistik, dilakukan uji post-hoc untuk membandingkan antar waktu pengukuran pada kedua kelompok.

\section{HASIL}

Penelitian ini melibatkan 30 pasien yang terbagi rata secara acak menjadi kelompok kontrol dan perlakuan. Terdapat perbedaan dinamika MAP pada kelompok perlakuan dengan flushing epinefrin dengan kelompok tanpa flushing epinefrin. Pada kelompok yang diberikan flushing epinefrin dapat dilihat bahwa perubahan MAP pada kelompok ini jauh lebih stabil jika dibandingkan pada kelompok yang tidak diberikan flushing epinefrin. Perubahan nilai MAP yang drastis didapatkan pada saat memasuki menit ke 6. Hasil pemantauan MAP ditampilkan pada tabel 1 dan Gambar 1.

Data perbedaan MAP serta profil lipid (kolesterol total dan trigliserida) pada kelompok yang menggunakan flushing epinefrin dan tidak menggunakan flushing epinefrin berdistribusi normal yang ditunjukkan dengan nilai $p>0,05$, sehingga uji statistik dilanjutkan dengan menggunakan Repeated measure Anova. Pada uji multivariat kelompok tanpa flushing epinefrin didapatkan nilai kemaknaaan sebesar $<0.05$. Pada uji berpasangan ditemukan pada menit ke 2-4, dan 8-10 masing-masing tidak ditemukan adanya perbedaan yang bermakna. Akan tetapi, pada pengukuran dimenit 4-6 dan 6-8 didapatkan adanya perbedaan yang bermakna $(\mathrm{p}<0.05)$. Pada uji multivariat kelompok dengan flushing epinefrin ditemukan nilai kemaknaan sebesar $>0.05$, dengan demikian tidak terdapat dua hasil pengukuran yang berbeda signifikan pada kelompok ini.

Pada penelitian tidak ditemukan perbedaan yang bermakna antara kadar trigliserida dan kolesterol total darah yang dinilai ketika pada awal tindakan operatif dan 12 jam paska operatif $(p>0.05)$. Oleh karena itu, dapat disimpulkan bahwa kadar kolesterol dan trigliserida tidak menunjukan perubahan pada kelompok yang diberikan flushing epinefrin dan tidak diberikan flushing epinefrin ketika dilakukan tindakan Cemented Hip Arthroplasty.

\section{PEMBAHASAN}

Penurunan tekanan darah dalam berbagai derajat setelah implantasi semen tulang menunjukkan bahwa implantasi semen tulang memiliki pengaruh yang signifikan pada hemodinamik. Penggunaan flushing epinefrin pada langkah medullary cavity flushing dapat menstabilkan MAP. Hal ini dapat dilihat dari hasil penelitian yang menunjukan adanya stabilitas dari penurunan tekanan darah ketika dilakukan implantasi semen tulang dimana pada pemberian flushing epinefrin didapatkan penuruan MAP yang minimal dan lebih stabil jika dibandingkan dengan kelompok yang tidak menggunakan epinefrin. Pada gambar 1 menunjukan bahwa kelompok dengan flushing epinefrin mulai mengalami penurunan MAP 
Tabel 1 Distribusi MAP dan Profil Lipid Sampel Penelitian

\begin{tabular}{lcc}
\hline Variabel & $\begin{array}{c}\text { Rerata Kelompok } \\
\text { Kontrol (SD) }\end{array}$ & $\begin{array}{c}\text { Rerata Kelompok } \\
\text { Intervensi (SD) }\end{array}$ \\
\hline MAP & $89,3(10,3)$ & $93,2(6,1)$ \\
Menit ke-2 & $83,8(10,7)$ & $90,5(6,6)$ \\
Menit ke-4 & $73,3(11,4)$ & $87,3(6,4)$ \\
Menit ke-6 & $81(10,9)$ & $84,3(6,9)$ \\
Menit ke-8 & $82,6(10,6)$ & $87,3(6,3)$ \\
Menit ke-10 & & $79,3(17,3)$ \\
Profil Lipid & $79,5(37,3)$ & $77,5(13,7)$ \\
Trigliserida Preoperasi & $84,4(29,5)$ & $154,6(39,5)$ \\
Trigliserida Paskaoperasi & $165,1(41,1)$ & $158,9(21,6)$ \\
Kolesterol Total Preoperasi & $161,2(46,2)$ & \\
Kolesterol Total Paskaoperasi & & \\
\hline
\end{tabular}

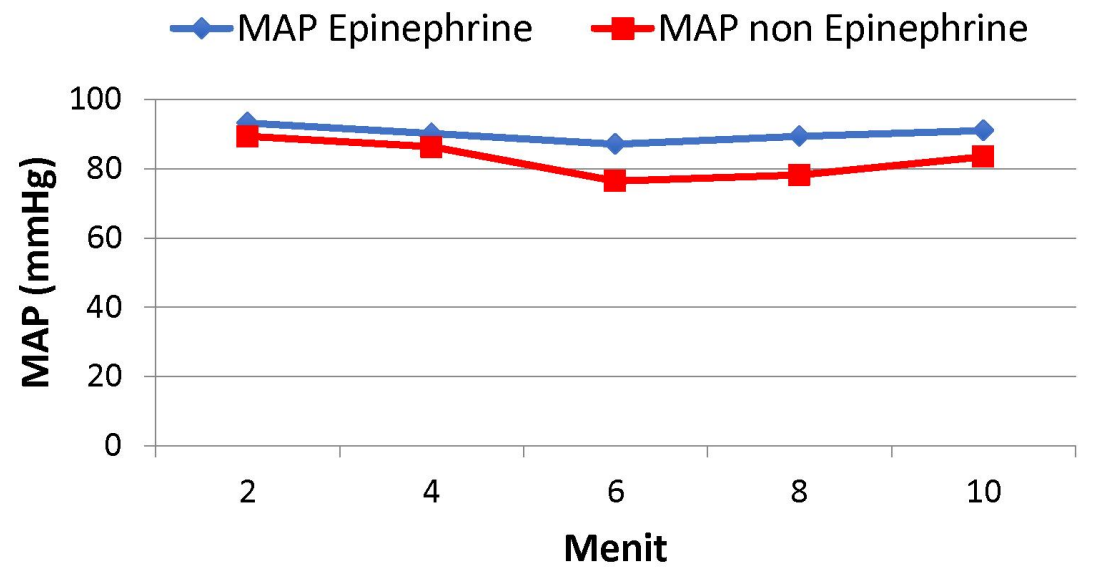

Gambar 1 Perubahan MAP seiring waktu pada kedua kelompok

sejak menit ke -2 , kemudian turun stabil sekitar $3 \mathrm{mmHg}$ setiap interval 2 menit sejak implantasi semen hingga menit ke -6 . Tekanan darah akan berangsur kembali ke normal sejak menit ke -8 . Sebaliknya, pada kelompok kontrol didapatkan penurunan MAP yang jauh lebih signifikan, yaitu didapatkan penurunan rerata MAP sekitar $12 \mathrm{mmHg}$ dari awal implantasi semen hingga menit ke -6 . Walaupun demikian, sama seperti kelompok yang menggunakan flushing epinefrin, didapatkan kenaikan nilai MAP kembali pada menit ke -8 hingga ke -10 .

Hasil penelitian ini didukung oleh penelitian serupa yang dilakukan oleh Qi et al, dimana penurunan tekanan darah sistolik, diastolik dan MAP dimulai sejak 1 menit setelah implantasi dan mulai menunjukan penurunan yang signifikan pada menit ke-2 hingga ke-6 setelah implantasi semen. Setelah menit ke-7 didapatkan bahwa tekanan darah kembali menuju nilai normal seperti sebelum dilakukan implantasi. ${ }^{14}$ Jika dibandingkan dengan penelitian yang dilakukan oleh Mehran et al, didapatkan perbedaan mengenai waktu puncak penurunan dari MAP pasien yang dilakukan operasi Cemented Hip Arthroplasty, dimana didapatkan penurunan tertinggi dari nilai MAP terjadi pada saat menit ke - 5 setelah dilakukan pemasangan semen dengan rata - rata penurunan sebesar $14 \mathrm{mmHg}$ pada kelompok pasien yang tidak menggunakan flushing epinefrin. ${ }^{15}$

Perubahan nilai MAP ini mungkin terjadi karena efek samping dari monomer semen tulang, yang menyebabkan pembentukan gumpalan darah kecil dan menyebabkan emboli paru ringan. Ini dapat menyebabkan penurunan curah jantung ataupun aritmia yang semakin memperberat penurunan tekanan darah. Memtsoudis dkk. menganggap bahwa terjadinya komplikasi kardiovaskular yang fatal dapat dikaitkan dengan aksi gabungan sejumlah faktor seperti hipovolemia, disfungsi miokardium, aritmia, emboli, dan pelepasan histamin. Pada pasien usia lanjut, dimana fungsi organ sistemik menurun terutama cadangan fungsional kardiopulmonal yang tidak mencukupi untuk menerima stress pembedahan. ${ }^{16}$

Pemberian flushing epinefrin intramedula memberikan efek vasokonstriksi pembuluh darah intramedula sehingga mengurangi masuknya partikel MMA ke dalam sirkulasi sistemik. Pada penelitian yang dilakukan oleh Qi et al. dikatakan bahwa pemberian flushing epinefrin intramedula terbukti mencegah terjadinya reaksi hipotensi yang ditimbulkan paska penggunaan bone cement pada prosedur Arthroplasty. ${ }^{14}$ Walaupun demikian, perlu diperhatikan bahwa penggunaan semen tulang pada acetabulum sebelum pemasangan implant acetabulum tidak menimbulkan terjadinya perubahan hemodinamik. ${ }^{17}$ Penggunaan semen tulang pada actebulum tidak diikuti peningkatan tekanan yang mencukupi untuk mendorong masuknya artikel MMA ke dalam sirkulasi sistemik. Oleh karena itu penggunaan flushing epinefrin lebih tepat pada pemasangan implant di tulang panjang yang menghasilkan tekanan intramedula lebih tinggi dibandingkan pada acetabulum. Alasannya adalah karena pembuluh darah intramedula yang terbuka akibat proses reaming dapat diatasi dengan efek vasokonstriksi dari epinefrin. Selain adanya efek tekanan intramedula, proses lain yang melibatkan adanya gangguan sistemik pada penggunaan semen tulang pada Arthroplasty sendi panggul adalah adanya reaksi eksotermic pada semen. Reaksi eksotermik ini memimbulkan panas yang dapat menimbulkan thrombosis lokal. ${ }^{18}$ Thrombosis lokal tersebut dapat lepas sehingga menimbulkan emboli pada jantung dan paru. 
Pada penelitian ini juga dievalusai pengaruh pemberian flushing epinefrin intramedula sebelum pemberian semen tulang terhadap kadar profil lipid yaitu kolesterol dan trigliserida sebelum pembedahan dan 12 jam setelah pembedahan jika dibandingkan dengan kelompok kontrol. Uji statistik tidak menunjukan adanya perbedaan yang bermakna secara statistik antara kelompok perlakuan dengan kelompok kontrol. Hasil penelitian ini, didukung oleh hasil studi lainnya yang dilakukan oleh Lehman dan Moore yaitu didapatkan bahwa tingkat rata-rata untuk trigliserida dan tidak berubah secara signifikan setelah tindakan reaming, lavage setelah reaming, pressurisation semen atau pemberian semen setelah lavage. ${ }^{9}$ Penelitian yang sama oleh Schele dkk, menemukan bahwa tidak ada perbedaan statistik baik dalam kadar trigliserida atau kolesterol pada tindakan pemberian semen setelah lavage dibandingkan dengan hanya pemberian semen saja,. ${ }^{19}$ Walaupun demikian hasil ini belum dapat menyangkal teori yang menyebutkan bahwa kilomikron plasma yang diaglutinasi merupakan sumber kemungkinan emboli lemak dan keberadaan suatu zat yang mengurangi stabilitas emulsi lemak plasma. ${ }^{9,20}$ Oleh karena itu, penelitian yang lebih spesifik untuk menjawab hipotesis tersebut perlu dilakukan.

\section{SIMPULAN}

Flushing epinefrin paska implantasi semen pada prosedur Cemented Hip Arthroplasty menghasilkan penurunan MAP yang minimal dibandingkan flushing tanpa epinefrin. Akan tetapi, flushing epinefrin tidak memberikan perbedaan pada kadar kolesterol dan trigliserida paska operasi.

\section{KONFLIK KEPENTINGAN}

Tidak ada.

\section{ETIKA PENELITIAN}

Penelitian ini telah mendapat persetujuan etik oleh Komisi Etik, Fakultas Kedokteran Universitas Udayana/RSUP Sanglah Denpasar, Bali, Indonesia sebelum penelitian berjalan (no. 152/ UN14.2.2.VII.14/LP/2019).

\section{PENDANAAN}

Penulis bertanggung jawab terhadap pendanaan penelitian ini tanpa melibatkan pihak sponsor, beasiswa, ataupun sumber pendanaan lainnya.

\section{KONTRIBUSI PENULIS}

Seluruh penulis berkontribusi terhadap penelitian ini baik dari perencaan proposal penelitian, pencarian data, analisis data penelitian, hingga interpretasi dan penyusunan naskah publikasi.

\section{DAFTAR PUSTAKA}

1. A.J. Donaldson, H.E. Thomson, N.J. Harper, N.W. Kenny N.W. Bone cement implantation syndrome (BCIS). Br J Anaesth. 2009.

2. Cooper H.J., Della Valle C.J. The two-stage standard in revision total hip replacement. Bone Joint J. 2013.

3. Griffiths R., Parker M. Bone cement implantation syndrome and proximal femoral fracture. British journal of anaesthesia. 2015.

4. Peters C.L., Randall R.L., Rothberg D.L., Kubiak E.N., Aoki S.K. Reducing the Risk of Bone Cement Implantation Syndrome During Femoral Arthroplasty. Orthopedics. 2013.

5. Curatolo C.J., Anderson M.R. Bone cement implantation syndrome. In: Decision-Making in Orthopedic and Regional Anesthesiology: A Case-Based Approach. 2015.

6. Olsen F., Kotyra M., Houltz E., Ricksten S.E. Bone cement implantation syndrome in cemented hemiarthroplasty for femoral neck fracture: Incidence, risk factors, and effect on outcome. Br J Anaesth. 2014.

7. Helgason C.M. Thrombophilia in ischemic stroke subtypes: Implications for treatment. Curr Treat Options Cardiovasc Med. 2006.

8. Wiryadana K.A., Supadmanaba I.G.P., Samatra D.P.G.P. Progress and potential roles blood biomarkers of ischemic stroke in clinical setting. Indones J Biomed Sci. 2017;11(2):19-29.

9. Lehman E.P., Moore R.M. Fat embolism: including experimental production without trauma. Arch Surg. 1927;14(3):621-62.

10. Elmaraghy a W., Humeniuk B., Anderson G.I., Schemitsch E.H., Richards R.R. The role of methylmethacrylate monomer in the formation and haemodynamic outcome of pulmonary fat emboli. J Bone Joint Surg Br. 1998.

11. Vaidya S. V., Thomas P. Sculco, Dennis D.A., Parvizi J. Basics in Hip and Knee Arthroplasty. 2015. 432 p.

12. Breusch S.J., Reitzel T., Schneider U., Volkmann M., Ewerbeck V., Lukoschek M. [Cemented hip prosthesis implantation--decreasing the rate of fat embolism with pulsed pressure lavage]. Orthopade. 2000.

13. Breusch S.J., Schneider U., Kreutzer J., Ewerbeck V., Lukoschek M. [Effects of the cementing technique on cementing results concerning the coxal end of the femur]. Orthopade. 2000.

14. Qi X., Zhang Y., Pan J., Ma L., Wang L., Wang J. Effect of Bone Cement Implantation on Haemodynamics in Elderly Patients and Preventive Measure in Cemented Hemiarthroplasty. Biomed Res Int. 2015.

15. Soleimanha M., Sedighinejad A., Haghighi M., Nabi B.N., Mirbolook A.R., Mardani-Kivi M. Hemodynamic and Arterial Blood Gas Parameters during Cemented Hip Hemiarthroplasty in Elderly Patients. Arch bone Jt Surg. 2014;2(3):163-7.

16. Boger A., Bohner M., Heini P., Verrier S., Schneider E. Properties of an injectable low modulus PMMA bone cement for osteoporotic bone. J Biomed Mater Res - Part B Appl Biomater. 2008.

17. Parvizi J., Saleh K.J., Ragland P.S., Pour A.E., Mont M.A. Efficacy of antibiotic-impregnated cement in total hip replacement. Acta Orthop. 2008. 
18. Blades M.C., Moore D.P., Revell P.A., Hill R. In vivo skeletal response and biomechanical assessment of two novel polyalkenoate cements following femoral implantation in the female New Zealand White rabbit. J Mater Sci Mater Med. 1998.

19. Scheele C., Pietschmann M.F., Schröder C., Grupp T. Holderied M., Jansson V., et al. Effect of lavage and brush preparation on cement penetration and primary stability in tibial unicompartmental total knee arthroplasty: An experimental cadaver study. Knee. 2017
20. Kerstell J., Hallgren B., Rudenstam C.M., Svanborg A. The chemical composition of the fat emboli in the postabsorptive dog. Acta Med Scand Suppl. 1969;499:3-18.

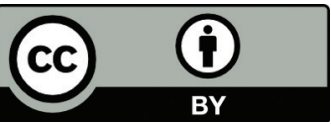

This work is licensed under a Creative Commons Attribution 